\title{
Daniel Veronese, de la periferia al centro de la nueva dramaturgia argentina
}

\section{Lucas Rimoldi}

Actualmente Daniel Veronese (Buenos Aires, 1955) se encuentra ubicado en el centro del canon teatral argentino, así como en otra etapa de su historia lo estuvieron figuras como Osvaldo Dragún o Roberto Cossa. En el abanico plurifacético de la escena de hoy, como la de Rafael Spregelburd y como la de Javier Daulte, la poética de Veronese se destaca y viene cobrando con los años un peso cada vez mayor. Director, dramaturgo e intérprete/ titiritero, algunas de sus obras como autor son Crónica de la caída de uno de los hombres en ella, Del maravilloso mundo de los animales: Los corderos y Del maravilloso mundo de los animales: Conversación nocturna, Formas de hablar de las madres de los mineros mientras esperan que sus hijos salgan a la superficie, XYZ. Varias de sus piezas han sido traducidas y representadas en Europa. Por ejemplo, Editions Théàtrales publicó Musique brisée y Adela, chemises sport/ femme/ manches longes/ couleur blanc y Hors Série "Du théàtre" editó Fugue équivoque d'une jeune fille serrant un mouchoir de dentelle sur sa poitrine.

La capitalización del prestigio ganado en la escena independiente en los últimos años le permite a Veronese hoy desarrollar actividades como la curaduría del Festival Internacional de Teatro de Buenos Aires o la dirección de obras en el circuito comercial, como El método Gronholm (Buenos Aires, 2005). Este alto grado de legitimación tiene mucho que ver con su condición de fundador de uno de los grupos más destacados dentro del contexto de la nueva dramaturgia argentina, surgida en el período de la postdictadura (Dubatti 33-34): El periférico de objetos, cuya singular propuesta teatral se basa en un trabajo de radical experimentación con objetos y muñecos. Sus otros integrantes son Ana Alvarado, Emilio García Wehbi y Alejandro Tantanián, 
con quienes Veronese se conoció hacia 1987 trabajando en el área de títeres del Teatro General San Martín, el complejo de salas oficiales más importante de la ciudad de Buenos Aires y de Argentina. El primer espectáculo del grupo fue Ubú Rey de Alfred Jarry (1990), al que siguieron Variaciones sobre B... (1991), la puesta de Máquina Hamlet de Heiner Müller (1995) y Circonegro (1996), pieza original de Daniel Veronese co-dirigida con Ana Alvarado, a la que considero el mejor espectáculo del grupo, cuya calidad no ha podido igualar su última producción, Apócrifo I: el suicidio (2002). Las otras producciones del grupo son Cámara Gessell, Zooedipous (1998) y Monteverdi Método Bélico (2000).

Por estos espectáculos El periférico ha recibido el reconocimiento de la prensa especializada del país y del exterior y numerosas distinciones: Premio Arlequín 1991, Premio Asociación de Cronistas del Espectáculo (ACE) 1995 por Cámara Gessell y 1996 por Máquina Hamlet; también el Leónidas Barletta, el Ollantay, María Guerrero, y una distinción especial de ACE a los diez años de trayectoria en 1999. Además de una sólida posición en el mapa teatral local, el grupo ha alcanzado una importante proyección en el exterior (naturalmente aprovechada por sus integrantes para sus proyectos individuales, como apunté antes respecto de la edición de textos de Veronese en Francia) merced a la originalidad de su estética y por su presencia en numerosos festivales internacionales de teatro tanto de América como de Europa: en 1999 estuvieron en Avignon, Montreal, Lisboa; en 1998 en Guanajuato, Belo Horizonte, Bruselas, París, Estrasburgo; en 1997 en Caracas, Bayona, Cádiz, Madrid, Roma, Montevideo; y en 1996, en Santiago de Chile, San Pablo, Porto Alegre, Hamburgo y Nueva York, entre otros. Como una de las consecuencias de estas múltiples giras, Monteverdi Método Bélico y Apócrifo I: el suicidio contaron con aportes de festivales y teatros extranjeros.

Pasando a la producción de Veronese fuera del grupo, algunos de sus últimos espectáculos, todos presentes en la cartelera de Buenos Aires en 2004, son:

- La forma que se despliega: estrenada en el Teatro Sarmiento del Complejo Teatral de Buenos Aires en el contexto del ciclo Biodramas en la temporada 2003 y repuesta en 2004 en la sala El camarín de las Musas, con la incorporación de otro personaje femenino al trío original y el recambio de los dos intérpretes masculinos. Dentro del corpus de cuatro obras que voy a tratar, la considero el mejor trabajo. 
- Open House: en el Espacio Callejón, se plantea como una suerte de work in progress en el que los actores se dan cita para representar una obra que debe continuar todos los lunes a las 21 hs.

- Mujeres soñaron caballos: estrenada hace tres años también en el Espacio Callejón, realizó funciones en El camarín de las Musas durante 2003 y 2004.

- Por último la más reciente: Un hombre que se ahoga, versión de Tres hermanas de Anton Chéjov estrenada en 2004 en El camarín de las Musas.

Esta importante productividad permite calibrar el presente del grupo de dramaturgos argentinos de elite, hecho confirmado por la agenda actual de teatristas como Tantanián, Spregelburd o Daulte. Con obras sembradas por diversas salas y territorios teatrales de la ciudad, incluso cruzando los circuitos off y oficial, más alguna esporádica incursión en el teatro comercial, su metodología de trabajo y la estrategia de legitimación dentro del campo cultural privilegia la presencia múltiple a la obsesión sobre el detalle. Esto no implica tildarlos de desprolijos, aunque algunas de sus propuestas resulten desparejas (en el caso de Spregelburd, la faraónica Bizarra no tenía la precisión suiza de La estupidez; en cuanto a Veronese, Open House ni Apócrifo I: El suicidio pueden equipararse a La forma que se despliega o Circonegro).

Esta estrategia de posicionamiento explica que durante 2004 en la sala Teatro del Pueblo pudieran verse los domingos simultáneamente $L a$ estupidez y El pánico de Spregelburd (hecho que tiene especial significación si pensamos en la complejidad de las obras, su duración (más de tres horas en el caso de La estupidez), la cantidad de actores que intervienen en ellas. Y salvo Open House, las tres obras de Veronese tuvieron cada una de ellas, en el mismo período, varias funciones durante los fines de semana en El camarín de las Musas, sin contar con que en la misma temporada, por ejemplo, éste dirigió a Eduardo Pavlovsky en La muerte de Marguerite Duras y participó del ciclo de intercambio con Francia denominado Tintas Frescas.

Antes de comentar algunos aspectos de las piezas mencionadas, me voy a detener en ciertas características del trabajo de $E l$ periférico que se manifiestan en ellas. A partir de Variaciones sobre B... el grupo instituyó la incorporación del manipulador como personaje visible en escena como una de las operatorias estructuradoras de su poética, procedimiento logrado mediante disociaciones, divisiones y multiplicaciones, en un complejo juego 
de dobles: los manipuladores-actores interactúan con los muñecos que manejan, con los títeres manipulados por otros, y entre sí, en una dinámica que tiende a homologar, a los ojos de los espectadores, el estatuto escénico de personas y muñecos. El refinamiento de la técnica genera una impactante ilusión de vida independiente de los muñecos pese, justamente, a que el manipulador esté completamente a la vista del espectador. Además, en varias de sus puestas han tematizado metateatralmente las relaciones entre el creador y el objeto creado, muchas veces explorando zonas afectivas ligadas a la frustración, al desengaño y la violencia, territorios donde vuelven a situarse los cuatro espectáculos de Veronese arriba enumerados.

Por ejemplo, en Variaciones sobre B... los manipuladores con sus rostros cubiertos por barbijos observaban las tribulaciones y movimientos titubeantes de un muñequito abandonado sobre una gran mesa. Circonegro incluía un número en el que un manipulador, haciendo las veces de asistente de su muñeco en un acto de hipnotismo, ponía en evidencia su carácter incompleto y ficticio, pasaje que culminaba con la destrucción repentina del títere, al cual el actor hacía estallar en mil pedazos sobre el piso del escenario. Para El periférico el trabajo con pequeñas muñecas antiguas de porcelana (descascaradas, sin ojos o pelo), con fragmentos de ellas, con muñecos gigantes o con actores, depende simplemente de cual opción sea teatralmente más eficaz para determinada acción: puesto que algunas, por limitaciones físicas o implicancias éticas, no pueden ejercerse sobre personas, y otras los muñecos no pueden ejecutarlas.

Estos aspectos reaparecen en el trabajo de dirección de actores de Veronese. Seres manipulados, seres-objeto que intentan sublevarse y cobrar vida, en el final de Mujeres soñaron caballos Lucera (una extraña niñarehén-objeto) asesina al resto de los personajes dejándolos tirados como monigotes. También en La forma que se despliega se retoma este abordaje de la relación creador/criatura, por un lado a través de la indagación sobre los estados y sentimientos que despierta la muerte de un hijo y por otro por la alusión a los vínculos entre director/actor/personaje. La obra consiste en una suerte de extraña confesión de una pareja ante un tercero, en lo que parece ser una sesión terapéutica donde ésta verbaliza su historia, rondando el tema de la muerte de su pequeño hijo. Pero al final de la pieza entendemos repentinamente que esa pareja que habló de temas tan traumáticos durante todo el espectáculo es simplemente un par de actores tal vez contratado por el "oyente," hasta ese momento una suerte de bizarro y alienado "falso analista" pero entonces, verdadero protagonista de la tragedia: "Pianista: Es 
terrible que estos niños mientan y actúen de esta manera el dolor ajeno. Lloran con tanta verdad por el hijo y yo no puedo.... Estos niños mintieron bien. (Toca y canta.) Son actores" (Veronese 2004, 47). Nuevamente las inversiones y los actores-muñecos-objetos que intercambian roles, nuevamente las reflexiones sobre las relaciones perversas entre manipulador y manipulado.

Ya sea en proyectos individuales o con el grupo, Veronese trabaja con una concepción de lo teatral como espacio de permanente indagación de lo subjetivo, especialmente en relación con aquellas zonas obscenas de la cultura que, en el sentido psicoanalítico del término tal como lo definió Freud en su ensayo sobre lo siniestro, deben quedar ocultas y excéntricas. El trabajo sobre el efecto de lo siniestro, que atraviesa las piezas comentadas, ha sido expuesto por el dramaturgo en un metatexto publicado en el año 1994 en $L a$ hoja del Rojas con motivo del estreno del espectáculo Música rota sobre piezas suyas, dirigido por Rubén Szchumacher. Decía allí Veronese: "La apariencia, la sospecha de que un hecho es familiar y reconocido, pero que al mismo tiempo también puede pertenecer a alguna otra raza ignota, debe flotar y desaparecer continuamente en el escenario" (Veronese 1994).

La batería de operatorias con las que trabaja este dramaturgo deconstruye los procedimientos realistas en el diseño escénico y los socava en la concepción de los personajes, aspectos a los que se suma una frecuentación de la autorreferencia y lo metateatral y el abordaje de temas socialmente considerados tabú, lo cual permite, en sus espectáculos más logrados, una poética articulación de lo obsceno, provocando en y con ellos un movilizador develamiento de lo que debe quedar en la penumbra, desplazado de la luz central de la escena y de la cultura. Develamiento, muchas veces manifestación repentina, de una violencia latente sólo apaciguada con la melancólica o humorística poeticidad de otras imágenes que, afortunadamente para equilibrio del espectador, se generan en el escenario. En palabras del autor: "Hago teatro para hacer visible lo que culturalmente de ninguna forma y bajo ningún pretexto puede serlo.... Lo que se verá será doblemente visible ya que ese hecho se alumbra por sobre el resto escenificado... teatro de lo obsceno" (Veronese 1994).

Las temáticas tabú que aparecen en todas estas piezas son la muerte (la del hijo en La forma que se despliega, el genocidio aludido y el crimen múltiple explícito en Mujeres soñaron caballos), y la cuestión del fracaso personal ante la vida, que puede considerarse un tema urticante en el contexto de una sociedad como la contemporánea que homologa existencia a éxito y por consiguiente relega a la exclusión, desaparición - o, en el mejor de los 
casos, al olvido - a aquellos que no alcanzan una realización social acorde a los estándares impuestos. Tema éste que se subraya en Un hombre que se ahoga en el personaje de Andrei y en los monólogos de Chebutikin y Vershinin, y que aparece claramente enunciado por uno de los personajes de Open House: "En la vida hay dos grupos de personas: uno muy pequeño que consigue lo que quiere, y una gran mayoría que no. El día que me di cuenta de que pertenecía al segundo grupo, me fui al patio, me senté debajo del árbol y me puse a mirar la sombra de las hojas como peces entre los ladrillos."

Como parte de su poética explícita, hay en la dramaturgia de Veronese una concepción del lenguaje que lo presenta como herramienta cognoscitiva y comunicativa insuficiente, deficitaria, concepción ligada al diseño de sujetos cuya identidad, en tanto entidad estructurante y unitaria, aparece estallada.

En efecto, y siguiendo a Gilles Deleuze y Félix Guattari, podemos decir que una suerte de lengua extranjera parece emerger de ciertos personajes (Lucera según la interpretación de Jimena Anganuzzi en Mujeres soñaron caballos es, al respecto, un caso paradigmático; algo similar ocurre con el "oyente" en La forma que se despliega). Alteraciones de la lengua materna que instalan también a muchos de los personajes de Un hombre que se ahoga en una zona de infrasciencia, de murmullos y balbuceos (Deleuze Guattari 1995, 153).

En todas estas piezas, los sujetos rompen con la familia y las instituciones sociales en una deriva que estremece y conmociona su subjetividad al punto de ponerlos en las fronteras del muro significante de la cultura. Descentramiento del sujeto racional tal como lo concibió la modernidad que es entendido por Deleuze y Guattari como devenir, en tanto manifestación de las pluralidades que nos atraviesan y nos dispersan en una desterritorialización subversiva respecto de los mandatos jerarquizantes, binarizantes y opresivos de la metafísica occidental. Según expresan estos autores, fundamentalmente en el artículo introductorio a Mil mesetas, "Rizoma," a diferencia de conceptos propios de las filosofías esencialistas y sustancialistas, la noción de devenir capta mejor el flujo de multiplicidades que vinculan maquínicamente a los diversos estratos de la realidad (DeleuzeGuattari 1997, 245).

Esta concepción de la subjetividad como puro devenir y desterritorialización puede percibirse de manera paradigmática en Open house, obra en relación a la cual dudaríamos de hablar de personajes y cuyos corpúsculos afectivos se limitan a deslizarse (descentrados, nómades, múltiples y a-jerárquicos, sin origen ni meta final) por sus propias líneas de 
fuga. La imposibilidad de conocer y comunicar aparece también manifestada en algunos personajes a partir de alteraciones corporales y psicomotrices. Alteraciones físicas que desarticulan una imagen de cuerpo jerárquica y ordenadamente concebido (un organismo), para constituir cuerpos caóticos y meramente afectivos, o cuerpos sin órganos (Deleuze-Guattari 1997, 164). Es el caso de Roger en la interpretación de Marcelo Subiotto en Mujeres soñaron caballos, o de Masha a cargo de Luciano Suardi en Un hombre que se ahoga. En este aspecto también se observa cómo la dirección de actores presupone la experiencia de radical experimentación con objetos y muñecos, desarticuladora de las ilusiones representativas del realismo, instauradora de otras: como la idea de que el extrañamiento y el mecanicismo de ciertas acciones logra per se ese efecto siniestro buscado en el espectador, cuando en realidad si el recurso no se dosifica y controla produce mero agobio, aburrimiento o distracción. Algo que tiende a suceder precisamente con los trabajos de los actores recién mencionados.

Interferencias sonoras de un pianito de juguete que percute el "oyente," duplicación de un piano envuelto en nylon sobre un costado de la escena en La forma que se despliega, y un violín ejecutado por Julieta Vallina en el rol de Andrei en Un hombre que se ahoga, parecen subrayar en las puestas el carácter musical de una dramaturgia que se piensa como partitura. Cancioncitas que buscan un centro estabilizador, un principio de orden en el seno del caos frente al peligro de la desintegración, son sonoridades que acumulan y movilizan fuerzas anticaóticas. Pero a veces se hace demasiado, se exagera, se opera con energías actorales no controladas, y se acaba produciendo un borroneo, una interferencia que altera los sonidos. El carácter desparejo de las actuaciones resiente esta concepción sonora de la interacción de los elementos escénicos. Osmar Nuñez, actor que trabaja en ambas obras, tiene a su cargo el parlamento de apertura de Un hombre que se ahoga, pero su estilo vocal demasiado impostado y cierta sobreactuación resultan, al respecto, contraproducentes. Un aire de improvisación poco pulida y escasez de síntesis podrían señalarse como otros tantos aspectos algo descuidados en la puesta en escena de la versión de Tres hermanas.

Veronese se ha hecho también cargo, en todas las piezas estudiadas, del diseño del espacio escénico, trabajando con las ideas rectoras de austeridad, deterioro, limpieza y claridad: escenarios despojados, muchos sillones de varios cuerpos. Open House se desarrolla en un espacio muy amplio prácticamente vacío; en el otro extremo, Mujeres soñaron caballos transcurre "dentro" de una escenografía deconstruidamente realista que 
representa el interior de un pequeño departamento de un bloque de viviendas económicas: todo sucede en ese espacio muy reducido al que, como espectadores, nos asomamos cual niños mirando dentro de una casa de muñecas peligrosa, en tanto sabemos que la amenaza agazapada en la extra escena tarde o temprano va a provocar un estallido. El programa de mano de la obra entregado a los espectadores reproduce en la portada un plano de la sala que incluye escenario y platea, y en el reverso la ampliación de las referencias técnicas relativas a la reproducción del departamento. Un hombre que se ahoga trabaja con un espacio rectangular cuyo perímetro colman sillas donde los actores permanecen cuando no intervienen protagónicamente en la escena. En el centro hay un sillón de varios cuerpos y algunas sillas; un armario y el violín son los restantes elementos escenográficos, esbozados en un plano de la sala (espacio escénico y plateas, sin especificaciones técnicas), dibujado en el reverso del programa de mano. Creo que el dispositivo escénico más interesante, una vez más, es el concebido para La forma que se despliega, puesto que múltiples sillones, algo destartalados para no desentonar con la propuesta general tal como la vengo explicando, se ubican directamente sobre el escenario y en ellos se sientan los espectadores, muy cerca de los actores. Evidentemente esto da una proximidad e inmediatez con el conflicto poco tranquilizadora, una co-implicancia buscada por el director, y que se acentúa en este caso.

La utilización de la luz es de una significación destacada, sobre todo en La forma que se despliega y Un hombre que se ahoga: una luz cruda, de tubos fluorescentes, que confluye en el intencional efecto de cercanía y descarnamiento en relación a las actuaciones y conflictos, en el exacerbamiento a la vez que develamiento del artificio del teatro, y en el alumbramiento focalizador y centralizador de lo que debería quedar en la penumbra.

En suma, se comprende en virtud de la cantidad y calidad de estos espectáculos y de otras obras de su autoría, por qué Daniel Veronese ocupa un lugar tan destacado y poco cuestionado dentro del campo teatral argentino, proyectándose al internacional con fuerza sostenida. Procedente de una nación pauperizada, de una sociedad en eterna crisis, su teatro no deja de ser una manera de contrarrestar este triste orden de las cosas.

\section{Buenos Aires, CONICET}


Fichas técnicas de los espectáculos:

*La forma que se despliega: Intérpretes: Stella Galazzi, Ernesto Claudio, Guillermo Arengo; Iluminación: Gonzalo Córdova; Autoría, musicalización, escenografía y dirección: Daniel Veronese.

* Mujeres soñaron caballos: Intérpretes: Jimena Anganuzzi, Héctor Bidonde, Osmar Nuñez, Silvina Sabater, Marcelo Subiotto, Julieta Vallina; Diseño de luces: Guillermo Arengo; Autoría, diseño escenográfico y dirección: Daniel Veronese.

*Un hombre que se ahoga: Intérpretes: Claudio Tolcachir, Luciano Suardi, Osmar Nuñez, Julieta Vallina, Osvaldo Bonet, Marta Lubos, Stella Galazzi, Silvina Sabater, Elvira Onetto, Silvina Bosco, Adriana Ferrer; Diseño de luces: Gonzalo Córdova; Diseño escenográfico y dirección: Daniel Veronese.

*Open House: Intérpretes: Melina Milone, Eugenia Iturbe, Julieta Petruchi, Mariana Paz, Nayla Pose, Juan Ignacio Alvarez Insúa, Olga Nani, Natalia Segre, Gustavo Antieco, Martín de Goycoechea; Diseño de luces: Gonzalo Córdova; Dramaturgia y dirección: Daniel Veronese.

\section{Bibliografía}

Deleuze, Gilles. Crítica y clinica. Barcelona, Ed. Paidós, 1995. y Félix Guattari. Mil mesetas. Capitalismo y esquizofrenia II. Valencia, Ed. Pre-textos, 1997.

Dubatti, Jorge. "Micropoéticas. Notas sobre la dramaturgia de Daniel Veronese," Nuevo teatro, nueva critica (Jorge Dubatti comp.). Buenos Aires, Ed. Atuel, 2000:29-46.

Veronese, Daniel. "Desde la periferia." La hoja del Rojas. Buenos Aires: Centro Cultural Ricardo Rojas, 1994. . La forma que se despliega. Revista Funámbulos 7. 21 ( 2004): 39-47. 